\title{
Mechanical properties and surface roughness of polymer-based materials containing DCPD particles
}

\author{
Mateus Silva VILELA(a) (iD) \\ Vitória Leão BERNAL(a) \\ Laura Luciana César CHAGAS(a) \\ Flávio Maron VICHI(b) (D) \\ Ana Cecília Corrêa ARANHA ${ }^{(c)}$ \\ Victor Elias ARANA-CHAVEZ ${ }^{\text {(d) }}$ \\ Roberto Ruggiero BRAGA(d) (D) \\ Marcela Charantola RODRIGUES(a) \\ (a) Universidade Cruzeiro do Sul, Graduate \\ Program in Dentistry, São Paulo, SP, Brazil. \\ (b) Universidade de São Paulo - USP, Institute \\ of Chemistry, Department of Fundamental \\ Chemistry, São Paulo, SP, Brazil. \\ (c) Universidade de São Paulo - USP, School \\ of Dentistry, Department of Operative \\ Dentistry, São Paulo, SP, Brazil. \\ (d) Universidade de São Paulo - USP, School of \\ Dentistry, Department of Biometarials and \\ Oral Biology, São Paulo, SP, Brazil.
}

Declaration of Interests: The authors certify that they have no commercial or associative interest that represents a conflict of interest in connection with the manuscript.

Corresponding Author:

Marcela Charantola Rodrigues

E-mail: marcela-cr@hotmail.com

https://doi.org/10.1590/1807-3107bor-2020.vol34.0095

Submitted: November 8, 2019

Accepted for publication: April 4, 2020

Last revision: July 17, 2020
Abstract: The purpose of this study was to synthesize dicalcium phosphate dihydrate (DCPD) particles functionalized with triethylene glycol dimethacrylate (TEGDMA) through different routes by varying the receptor solution: ammonium phosphate (AP groups) or calcium nitrate (CN groups) and the moment in which TEGDMA was incorporated: ab initio (ab) or at the end of dripping the solution (ap). Two syntheses were performed without adding TEGDMA (nf). The particles were characterized by X-ray diffractometry, true density (using a helium pycnometer), surface area, and scanning electron microscopy. A $20 \mathrm{vol} \%$ of DCPD particles from the D, E, and F groups was added to the resin matrix to determine the degree of conversion (DC), biaxial flexural strength (BFS), the flexural modulus (FM), and surface roughness after an abrasive challenge (RA). A group with silanized barium glass particles was tested as a control. The data were submitted to ANOVA/Tukey's test (DC, BFS, and RA), and the KruskalWallis test $(\mathrm{FM})($ alpha $=0.05)$. BFS values varied between 83 and 142 $\mathrm{MPa}$, and the $\mathrm{CN} \_$ab group presented a similar value (123 $\left.\mathrm{MPa}\right)$ to the control group. FM values varied between 3.6 and 8.7 GPa (CN_ab and CN_nf groups, respectively), with a significant difference found only between these groups. RA did not result in significant differences. The use of calcium nitrate solution as a receptor, together with ab initio functionalization formed particles with larger surface areas. Higher BFS values were observed for the material containing DCPD particles with a higher surface area. In general, the DC, FM, and RA values were not affected by the variables studied.

Keywords: Calcium Phosphates; Composite Resins; Flexural Strength.

\section{Introduction}

Restorative materials are inert, biocompatible, and mechanically resistant. However, new development strategies are focusing efforts on regenerative restorative biomaterials ${ }^{1}$ capable of reversing the progression of caries lesions due to increasingly prioritized minimal intervention. . $3,4^{2}$

The incorporation of particles consisting of different phases of calcium orthophosphates $(\mathrm{CaP})$ in resinous matrices, such as dicalcium phosphate dihydrate (DCPD), amorphous calcium phosphate (ACP), and tetracalcium phosphate (TTCP), are capable of releasing calcium and hydrogen 
phosphate ions into the surroundings. $5,6,7$. Resin composites containing $\mathrm{CaP}$ particles remineralize enamel and dentin., ${ }^{4,7} \mathrm{~A}$ significant reduction in dental enamel demineralization has been observed in situ when using composite containing ACP particles. ${ }^{3}$ Finally, these materials promote mineral recovery of enamel-dentin affected by caries in vivo. ${ }^{8}$

Unlike barium and silica glass particles commonly found in commercial materials, calcium phosphate particles do not act as strengtheners of restorative material. ${ }^{9}$ In contrast, the absence of a strong chemical interaction between the calcium phosphate particles and the polymer causes these particles to behave as large defects in the material, ${ }^{10}$ causing stress and creating potential sites for crack initiation. ${ }^{9,11}$ In fact, incorporating $20 \%$ mass of TTCP particles into a resin matrix causes a $50 \%$ reduction in strength. ${ }^{12}$ The strength of a material containing $20 \mathrm{vol} \%$ DCPD particles corresponds to less than half of the observed values for a silanized silica-containing composite. ${ }^{13}$ Thus, one of the main challenges moving forward with applications of these materials in clinical practice is to reconcile ion release with satisfactory mechanical properties. ${ }^{2,11}$

One of the alternatives proposed to increase the compatibility of these particles with the resin matrices is particle surface functionalization. ${ }^{14,15}$ Calcium phosphate particles, such as DCPD, are synthesized through very simple routes and can be functionalized at different times. Functionalization concomitant to particle precipitation (ab initio) was proposed with the objective of providing a chemical interaction with the resinous monomers and to reduce particle size. ${ }^{6,16,17}$ DCPD particles functionalized ab initio with the triethylene glycol dimethacrylate monomer (TEGDMA) forms higher surface area particles. ${ }^{17}$ In addition, up to a $40 \%$ increase in fracture strength values is observed when resinous materials containing functionalized DCPD particles were compared to materials with nonfunctionalized particles. ${ }^{6,13,18}$ DCPD functionalization after complete precipitation of particles has not been evaluated.

During coprecipitation synthesis of DCPD particles, the calcium nitrate solution is dripped onto an ammonium phosphate (AP) solution containing the functionalizing monomer. ${ }^{6,11,17,19}$ Switching the receptor solution may also lead to changes in particle size and morphology. Therefore, the aim of this study was to evaluate the effects of different routes of synthesis through coprecipitation, alternating the receptor solution and the moment of functionalization (ab initio or after particle precipitation) on the characteristics of DCPD particles. DCPD particles were added to resin matrices to analyze the degree of conversion (DC), mechanical properties, and surface roughness of the materials.

\section{Methodology}

\section{Synthesis and characterization of the particles}

DCPD particles were synthesized from solutions of ammonium phosphate $\left(\mathrm{NH}_{4}\right)_{2} \mathrm{HPO}_{4}$ and calcium nitrate $\mathrm{Ca}\left(\mathrm{NO}_{3}\right)_{2} \cdot 4 \mathrm{H}_{2} \mathrm{O}$ (Sigma-Aldrich Brazil Ltd.®, São Paulo, Brazil), both at a concentration of $0.2 \mathrm{~mol} / \mathrm{L}$. For particles functionalization, triethylene glycol dimethacrylate monomer (TEGDMA) was used at a molar ratio of 1:1 in relation to the ammonium phosphate solution. The experimental groups were defined by varying the recipient solution: ammonium phosphate solution (AP groups) and calcium nitrate solution (CN groups). The moment the functionalized monomer was incorporated was also a factor in the study; either added to the receiver solution before dripping ( $a b$ initio: ab groups) or at the end of the precipitation of the particles (after precipitation: ap groups). Two additional syntheses were performed without adding TEGDMA as controls (nonfunctionalized: $n f$ groups). The suspensions were shaken for 3 hours and the by-products as well as the excess TEGDMA (when added to the synthesis) were removed by rinsing and vacuum filtration. The final products were frozen and lyophilized to a white powder.

The particles were characterized by X-ray diffraction (XRD) with readings between $10^{\circ}$ and $60^{\circ}$, geometry $\mathrm{q} / 2 \mathrm{q}$, using nickel-filtered $\mathrm{CuK} \alpha$ radiation of $40 \mathrm{kV}$ and $30 \mathrm{~mA}$ (Rigaku-Multiflex, Tokyo, Japan). The percentage of monomer in the functionalized particles was determined indirectly by analyzing real density using a helium pycnometer 
(Ultrapyc 1200e, Quantachrome Instruments, Boynton Beach, USA). The surface area of the particles was evaluated using adsorption isotherms and the Brunauer-Emmett-Teller (BET) method with the aid of NOVAWin software (Quantachrome Instruments, Boynton Beach, USA). Particle morphology was observed under a scanning electron microscope (Quanta FEG600, Eindhoven, The Netherlands). A minimum of 25 particles from each group was measured using Image J software (National Institutes of Health, Bethesda, USA).

\section{Incorporation of the particles in the resinous material}

\section{Manipulation of experimental materials}

An organic matrix based on BisGMA (2,2-bis[4(2-hydroxy-3-methacryloxypropoxy)phenyl]-propane, Sigma-Aldrich Co., St. Louis, USA) and TEGDMA (2-methyl-2-propenoic acid, Sigma-Aldrich) in proportions of 1:1 (in mol). DMAEMA photo initiator (Sigma-Aldrich) and camphorquinone (Sigma-Aldrich, Steinhein, Germany) were added in $0.5 \%$ of weight; $20 \%$ of the volume of the DCPD particles was added to this matrix. Particles with the highest surface area in the previous section of the study were chosen for this evaluation. Resinous material containing 20\% of the volume of silanized barium glass particles $(0.5 \mu \mathrm{m})$ was used as a control.

\section{Degree of conversion}

The DC of the resin-based materials was determined by Fourier-transformed infrared spectroscopy (FTIR). ${ }^{20}$ Disk-shaped specimens were prepared $(\mathrm{n}=3 ; 7 \mathrm{~mm} \times 0.9 \mathrm{~mm})$. The spectrum of the unpolymerized material was obtained in the wavelength range of 4,000-9,840 $\mathrm{cm}^{-1}$ with a resolution of $6 \mathrm{~cm}^{-1}$ (Vertex 70, Bruker Optik GmbH, Etttlingen, Germany). A new spectrum was obtained after 24 hours of photopolymerization, with an energy density of $48 \mathrm{~J} / \mathrm{cm}^{2}\left(1,200 \mathrm{~mW} / \mathrm{cm}^{2} \times 40 \mathrm{~s}\right)$ and storage at $37^{\circ} \mathrm{C}$. The area under the vinyl bond absorption band located at $6,165 \mathrm{~cm}^{-1}$ was calculated with Opus v.6 software (Bruker Optics). The DC of the materials was obtained as the ratio of the absorption bands corresponding to carbon:

$$
D C=\left(1-\frac{\text { polymerized }}{\text { unpolymerized }}\right) \cdot 100
$$

\section{Biaxial flexural strength and modulus}

Disk-shaped specimens $(\mathrm{n}=10 ; 12 \times 1.2 \mathrm{~mm})$ were made using a split stainless steel matrix. The materials were inserted at one time and were photopolymerized for $40 \mathrm{~s}$ (10 s per quadrant). After 7 days of storage at $37^{\circ} \mathrm{C}$, the specimens were fractured in a universal test machine (model 5565, Instron Corp., Canton, USA) using the "piston-onthree-balls" accessory, at a loading rate of $0.5 \mathrm{~mm} / \mathrm{min}$. The biaxial flexural strength (BFS) was calculated in MPa using the equations:

$$
\begin{gathered}
\sigma_{B I}=\frac{-0,2387 P(X-Y)}{b^{2}} \\
X=(1+v) \operatorname{In}\left(\frac{r^{2}}{r^{3}}\right)^{2}+\left[\left(\frac{1-v}{2}\right)\right]\left(\frac{r^{2}}{r^{3}}\right)^{2} \\
Y=(1+v)\left[1+\operatorname{In}\left(\frac{r_{1}}{r_{3}}\right)^{2}\right]+(1-v)\left(\frac{r_{1}}{r_{3}}\right)^{2}
\end{gathered}
$$

Where $\mathrm{P}$ is the maximum fracture load (in $\mathrm{N}$ ); $\mathrm{b}$ is thickness of the disk (in $\mathrm{mm}$ ); $\mathrm{v}$ is the Poisson coefficient; $r_{1}$ is the radius of the circle on which the steel balls $(5.0 \mathrm{~mm})$ are positioned; $r_{2}$ is the radius of the tip of the piston or the area of load application $(0.6 \mathrm{~mm}) ; \mathrm{r}_{3}$ is the radius of the disk (in $\mathrm{mm}$ ). The Poisson coefficient adopted was 0.30 for all materials. ${ }^{21}$ The flexural modulus (FM) was calculated using the following equation:

$$
E=\frac{\beta P a^{2}}{\omega h^{3}}
$$

Where $\mathrm{E}$ is the FM (in GPa), $\beta$ is a constant related to disk deflection in the central region (0.509), $\mathrm{P}$ is the applied load (in N), a is the radius of the disk (in $\mathrm{mm}$ ), $\omega$ is the deflection at the center, and $\mathrm{h}$ is disk thickness (in $\mathrm{mm}$ ).

\section{Abrasive cycles and profilometry analysis}

For each experimental group, cylindrical specimens $(\mathrm{n}=10 ; 4 \times 5 \mathrm{~mm})$ were prepared and photopolymerized for $40 \mathrm{~s}\left(1,200 \mathrm{~mW} / \mathrm{cm}^{2}\right)$ and kept 
in an oven at $37^{\circ} \mathrm{C}$ for 7 days. The specimens were embedded in acrylic resin and then flattened with abrasive $\mathrm{Al}_{2} \mathrm{O}_{3}$ disks with grades of 220-, 400-, 600-, 1,200-, and 2,000- in polystyrene (Teclago, Vargem Grande Paulista, Brazil) and polished with a felt disk and diamond paste. A surface analysis was performed using an optical profilometer (Proscan 2000, Scantron, Venture Way, Tauton, UK) in a $2 \mathrm{~mm}$ length and $1 \mathrm{~mm}$ width of the surface of the specimens.

The edges of the test specimens were protected with UPVC (Graphic Tape, Chartpak, Leeds, USA) tape exposing an area corresponding to $1 \mathrm{~mm}$ in length in the center of the test specimens under analysis. The protected areas were used as the point of reference in the study after the abrasive challenge. The specimens were introduced into an automatic toothbrushing machine (MSEt - ELQUIP, São Paulo, Brazil), using machine-fixed brushes (Curaprox, Curaden Switzerland). A total of 20,000 brushing cycles were carried out with a load of $300 \mathrm{~g}$ at 180 cycles/min. A dilution of the dentifrice (Colgate Total 12, Colgate-Palmolive Co., São Paulo, Brazil) was used from 1 part to 3 parts deionized water. ${ }^{22}$ After the abrasion cycles, the loss of structure was evaluated using software (Proscan Application software v.2.0.17) to calculate the depth of the test area in relation to the reference areas.

\section{Statistical analysis}

The DC, flexural strength, and profilometry data were submitted to analysis of variance and Tukey's test $(\mathrm{a}=0.05)$ after an analysis of homoscedasticity. The FM data were heteroscedastic and were evaluated through the nonparametric Kruskal-Wallis test. A p-value $<0.05$ was considered significant.

\section{Results}

\section{Characterization of the particles}

The formation of DCPD crystalline structures was confirmed by the diffractograms with peak intensities at $11.6^{\circ}, 20.9^{\circ}, 23.6^{\circ}, 29.3^{\circ}, 35.5^{\circ}$, and $48^{\circ}$, respectively. The numerical results obtained in the characterization analyses (adsorption isotherms with the BET method and theoretical density) of the particles are presented in Table 1.

The inversion of the receptor solution at the time of synthesis, together with functionalization of the particles, had effects on the surface area of the particles. With the ammonium phosphate solution as a receptor (AP_ab, AP_ap, and AP_nf groups), the moment the monomer was added and the presence of the functionalizing agent did not significantly affect particle surface area. However, when the calcium nitrate solution was the receptor solution $\left(\mathrm{CN}_{-} \mathrm{ab}, \mathrm{CN}_{-}\right.$ ap and CN_nf groups), the DCPD particles presented a surface area up to 4.8 times higher when they were functionalized. In addition, the functionalization of the particles at the time of synthesis led to the formation of particles with the largest surface area (CN_ab group: $43 \mathrm{~m}^{2} / \mathrm{g}$, functionalization after synthesis CN_ap group: $25 \mathrm{~m}^{2} / \mathrm{g}$ ).

The theoretical density results allowed us to estimate the percentage of functionalizing monomer present in the particles, which varied between $38 \%$ and $59 \%$. Figure shows the images obtained by scanning electron microscopy. Functionalized particles with similar appearance on thin plates

Table 1. Characterization of DCPD particles according to synthesis conditions.

\begin{tabular}{|c|c|c|c|c|c|c|c|}
\hline Groups & Receiving solution & Functionalization & $\begin{array}{l}\text { Density } \\
(\mathrm{g} / \mathrm{mL})\end{array}$ & $\begin{array}{c}\text { TEGDMA content } \\
(\%)\end{array}$ & $\begin{array}{c}\text { Surface area } \\
\left(\mathrm{m}^{2} / \mathrm{g}\right)\end{array}$ & $\begin{array}{l}\text { Particle long } \\
\text { axis }(\mu \mathrm{m})\end{array}$ & $\begin{array}{c}\text { Particle width } \\
(\mu \mathrm{m})\end{array}$ \\
\hline$A P_{-} a b$ & Ammonium & $a b$ initio & 1.8 & 59 & 27 & 19 & 7 \\
\hline$A P \_a p$ & phosphate & after precipitation & 2.0 & 47 & 26 & 20 & 7 \\
\hline AP_nf & & & 2.8 & - & 20 & 21 & 9 \\
\hline CN_ab & Calcium & $a b$ initio & 2.1 & 38 & 43 & 19 & 8 \\
\hline CN_ap & nitrate & after precipitation & 1.9 & 50 & 25 & 22 & 10 \\
\hline CN_nf & & - & 2.7 & - & 9 & 29 & 11 \\
\hline
\end{tabular}



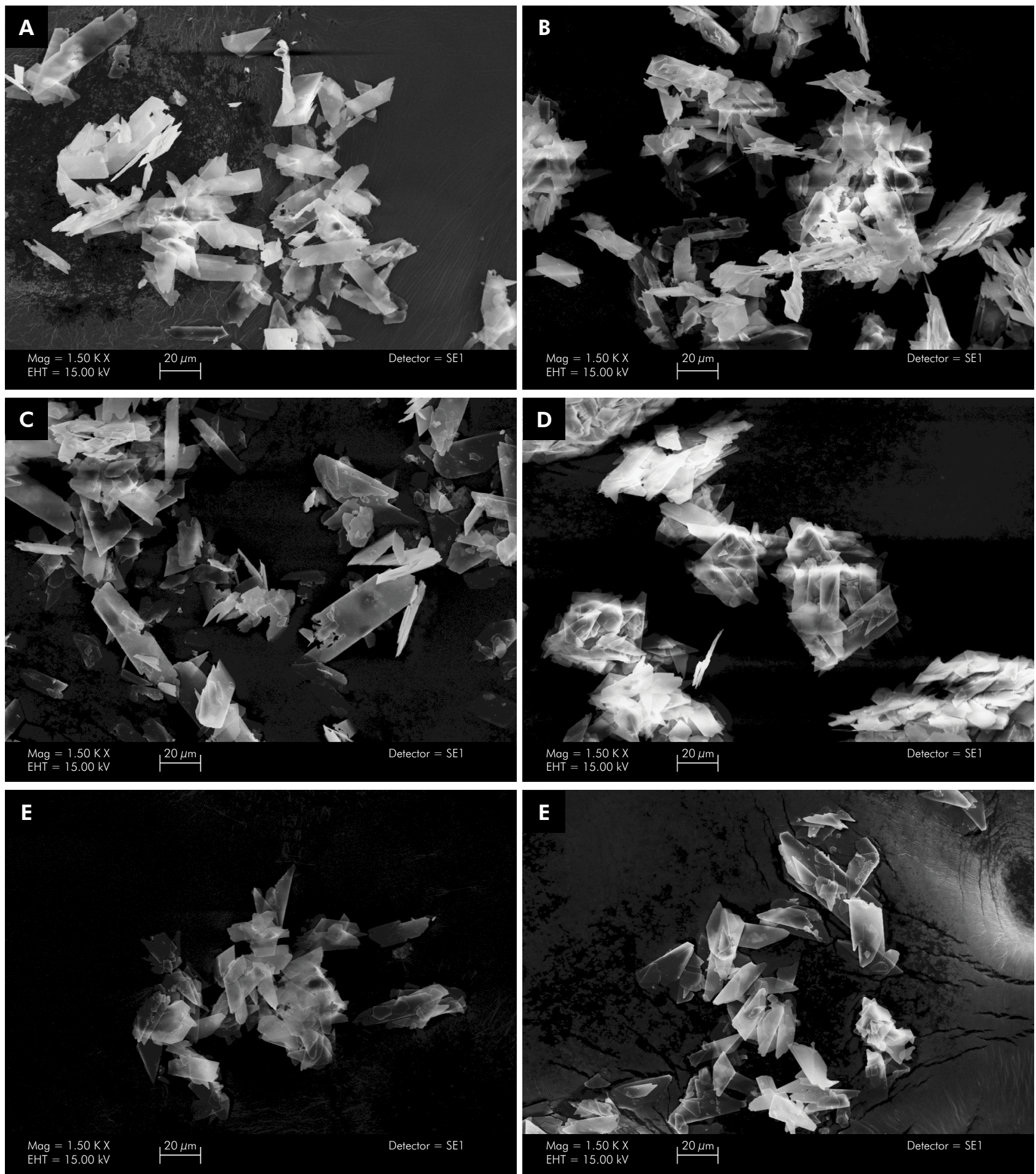

Figure. Scanning electron microscopic images of the groups of synthesized particles, with an increase of 1,500 times. A-C present particles synthesized with the ammonium phosphate solution as the receptor, functionalized during (AP_ab) or after synthesis (AP_ap) or without a functionalizing agent (AP_nf); and D-F illustrate the particles synthesized with the calcium nitrate solution as the receptor, functionalized during (CN_ab) or after synthesis ( $\left.C N \_a p\right)$ or without functionalizing (CN_nf). 
- Mechanical properties and surface roughness of polymer-based materials containing DCPD particles

Table 2. Means, standard deviations and statistical analysis of experimental groups submitted to biaxial flexural test and roughness analysis.

\begin{tabular}{lcccc}
\hline Groups & Degree of conversion (\%) & Biaxial flexural strength $(\mathrm{MPa})$ & Flexural modulus $(\mathrm{GPa})$ & Surface roughness $(\mu \mathrm{m})$ \\
\hline $\mathrm{CN} \_a b$ & $80.7(2.4)^{\mathrm{A}}$ & $122.5(28.7)^{\mathrm{A}}$ & $3.6(2.4)^{\mathrm{B}}$ & $2.0(0.8)^{\mathrm{A}}$ \\
CN_ap & $83.9(4.0)^{\mathrm{A}}$ & $86.9(15.0)^{\mathrm{B}}$ & $6.3(1.6)^{\mathrm{AB}}$ & $1.6(0.7)^{\mathrm{A}}$ \\
$\mathrm{CN}$ nf & $80.9(1.3)^{\mathrm{A}}$ & $83.0(14.6)^{\mathrm{B}}$ & $8.7(4.3)^{\mathrm{A}}$ & $1.8(0.6)^{\mathrm{A}}$ \\
Barium glass & $77.6(1.8)^{\mathrm{A}}$ & $142.4(23.3)^{\mathrm{A}}$ & $5.8(1.7)^{\mathrm{AB}}$ & $2.3(1.2)^{\mathrm{A}}$ \\
\hline
\end{tabular}

contained average dimensions of $20 \pm 10 \mathrm{~mm}$ in the long axis and $8 \pm 3 \mathrm{~mm}$ in width. The nonfunctionalized particles were slightly larger with average dimensions of $25 \pm 12 \mathrm{~mm}$ in length and $10 \pm 4 \mathrm{~mm}$ in width.

\section{Incorporation of the particles in the resin-based material}

The BFS, FM, and surface roughness results are presented in Table 2.

All tested materials had a similar DC ( $p>0.05)$. Only the CN_ab group presented strength similar to the control, while the CN_ap and CN_nf groups revealed flexural strength similar to each other but significantly lower than the $\mathrm{CN}_{-} \mathrm{ab}$ and control groups $(\mathrm{p}<0.001)$. The only significant difference in the FM was detected between the CN_nf and CN_ab groups $(p<0.05)$. Surface roughness varied between $1.6 \mu \mathrm{m}$ and $2.3 \mu \mathrm{m}$, and was similar among the groups $(p>0.05)$.

\section{Discussion}

A previous study reported an increase in the surface area of DCPD particles when TEGDMA was added to the synthesis ab initio. ${ }^{17}$ The present results confirm that finding and highlight the effect of a receptor solution on particle surface area. Furthermore, the presence of the monomer did not prevent the formation of DCPD, regardless of the drip solution, according to XRD.

The variables evaluated in this study did not affect the percentage of TEGDMA present on the DCPD particles. However, even with similar percentages of TEGDMA, surface area values were quite distinct, particularly for the CN_ab and CN_ap groups. Incorporating the functionalizing monomer into the receptor solution (prior to the reaction) may have produced particles with a larger area because TEGDMA has low acidity and can bind by chemisorption to the surface of particles, affecting their growth. However, this effect was only observed when the calcium nitrate solution was the receptor. The comparative analysis of the surface area results of the CN_ab and CN_ap groups suggested that incorporating the functionalizing agent after synthesis led to physical adsorption of the monomer on already formed DCPD particles. Considering the larger surface area of the particles obtained in the CN_ab group, the second phase of this study followed the application of the particles, which were synthesized with calcium nitrate as the receptor solution in a resinous organic matrix.

DCPD has two main characteristics that makes it suitable as ion-releasing particles in resin-based materials: a) DCPD has intermediate solubility among the phases of calcium orthophosphates, ${ }^{23}$ which favors ion release and $b$ ) the refractive index of the DCPD particles is $1.54 / 1.55$, which is very close to the refractive indices of the resin matrix $(1.50-1.55)^{15}$ and ensures light transmission during photopolymerization. The $20 \%$ volume fraction of added particles was determined by using the results obtained in an earlier in vitro study, as a reference in which materials containing percentages of 10 $\mathrm{vol} \%$ and $20 \mathrm{vol} \%$ of functionalized DCPD particles remineralized enamel lesions. ${ }^{4}$

Incorporating DCPD particles, regardless of functionalization, did not significantly affect the DC due to the compatibility of the refractive indices already discussed. Therefore, the results obtained from other tests cannot be attributed to 
differences in the DC. Studies that have evaluated materials containing other bioactive particles, such as unsilanized bioglass, have reported that incorporating similar percentages of particles causes a significant decrease in the DC value. ${ }^{24} \mathrm{In}$ previous studies, resin-based materials, which also contained 20\% DCPD particles functionalized $a b$ initio with TEGDMA, had lower flexural strength values than those found in this study. ${ }^{13}$ The DCPD particles in the previous study presented a lower TEGDMA percentage (8\%), resulting in a higher effective DCPD content in the material, which may explain the difference in the results. The BFS values of the CN_ab and control groups were similar. This result is very promising as it demonstrates that the DCPD particles possibly did not behave as material defects, and provided mechanical characteristics similar to material with a reinforcing filler.

It is well established that the interfacial bonds between the inorganic particles and the organic phase of composites are necessary to increase their mechanical strength because of the more efficient stress transfer mechanism between the particles and the resin matrix. ${ }^{25}$ However, the $\mathrm{CN}$ _ap group particles were functionalized and the strength value $(87 \mathrm{MPa})$ was similar to that of the group of nonfunctionalized particles (CN_nf group, 83 $\mathrm{MPa}$ ). A possible explanation for this finding may be that incorporating particles with a larger total surface area (group CN_ab) promoted a better interaction with the resin matrix. Notably, the differences observed in surface area among particles do not necessarily correspond to a smaller size on SEM, as these measurements represent a very small sample. Another hypothesis is related to the effective volume of DCPD particles present in the material is that a lower percentage of DCPD means a higher percentage of functionalizing monomer, which could in itself improve the mechanical behavior of the material. A similar mechanism is observed in composites containing bioglass, in which more adverse effects are observed in the flexural strength value when the percentage of bioglass is increased. ${ }^{26}$

The modulus of elasticity of a material is related to the stiffness of the particles and to the way they interact with each other in the resinous material. ${ }^{27}$ All materials containing DCPD particles presented FM values similar to the control group, with values between 3.6 and 8.7 GPa obtained for the CN_ab and $C N \_n f$ groups $(p<0.05)$. The observed difference between the particle densities, and consequently in the percentage of functionalized monomer, may be a contributing factor to the difference in modulus values considering that particles with higher density values increase the modulus values. ${ }^{28}$

This study also presents results of an evaluation of the roughness of resinous matrices containing DCPD after an abrasive challenge. The 20,000 cycles of brushing resembled approximately 2 years of brushing. ${ }^{29}$ The mechanical wear of the composites was reported as gradual removal of the polymeric matrix, ${ }^{29}$ in which unsupported fillers become more susceptible to exfoliation. ${ }^{30}$ No significant differences in the surface roughness values were observed between the groups after the abrasive challenge (1.6-2.3 $\mu \mathrm{m})$, even with a significant difference between the sizes of the barium glass particles and the DCPD particles. The DCPD particles may have fractured during the abrasion challenge due to their low hardness, regardless of particle size.

\section{Conclusions}

Considering the limitations of this study, we conclude that the calcium nitrate solution, as a receptor at the moment of synthesis, allowed the formation of higher surface area DCPD particles. Within these groups of particles (CN_ab, CN_ap, and $\left.\mathrm{CN} \_n f\right)$, the timing and presence of particle functionalization did not affect the DC or surface roughness after the abrasive challenge. In the BFS analysis, the resin with DCPD particles functionalized ab initio presented a behavior similar to that of resin containing conventional barium glass particles in a $20 \%$ volume.

\section{Acknowledgments}

The authors would like to express their gratitude to FGM Dental Products for donating the glass fillers and to Curaden Swiss Brazil for donating the Curaprox toothbrush. 
Mechanical properties and surface roughness of polymer-based materials containing DCPD particles

\section{References}

1. Ferracane JL, Giannobile WV. Novel biomaterials and technologies for the dental, oral, and craniofacial structures. J Dent Res. 2014 Dec;93(12):1185-6. https://doi.org/10.1177/0022034514556537

2. Marovic D, Tarle Z, Hiller KA, Müller R, Rosentritt M, Skrtic D, et al. Reinforcement of experimental composite materials based on amorphous calcium phosphate with inert fillers. Dent Mater. 2014 Sep;30(9):1052-60. https://doi.org/10.1016/i.dental.2014.06.001

3. Melo MA, Weir MD, Rodrigues LK, Xu HH. Novel calcium phosphate nanocomposite with caries-inhibition in a human in situ model. Dent Mater. 2013 Feb;29(2):231-40. https://doi.org/10.1016/j.dental.2012.10.010

4. Alania Y, Natale LC, Nesadal D, et al. In vitro remineralization of artificial enamel caries with resin composites containing calcium phosphate particles. J Biomed Mater Res B Appl Biomater. 2019 Jul;107(5):1542-50. https://doi.org/10.1002/ibm.b.34246

5. Rodrigues MC, Chiari MD, Alania Y, Natale LC, Arana-Chavez VE, Meier MM, et al. lon-releasing dental restorative composites containing functionalized brushite nanoparticles for improved mechanical strength. Dent Mater. 2018 May;34(5):746-55. https://doi.org/10.1016/i.dental.2018.01.026

6. Alania Y, Chiari MD, Rodrigues MC, Arana-Chavez VE, Bressiani AH, Vichi FM, et al. Bioactive composites containing TEGDMAfunctionalized calcium phosphate particles: degree of conversion, fracture strength and ion release evaluation. Dent Mater. 2016 Dec;32(12):e374-81. https://doi.org/10.1016/i.dental.2016.09.021

7. Weir MD, Ruan J, Zhang N, Chow LC, Zhang K, Chang X, et al. Effect of calcium phosphate nanocomposite on in vitro remineralization of human dentin lesions. Dent Mater. 2017 Sep;33(9):1033-44. https://doi.org/10.1016/i.dental.2017.06.015

8. Peters MC, Bresciani E, Barata TJ, Fagundes TC, Navarro RL, Navarro MF, et al. In vivo dentin remineralization by calcium-phosphate cement. J Dent Res. 2010 Mar;89(3):286-91. https://doi.org/10.1177/0022034509360155

9. Braga RR. Calcium phosphates as ion-releasing fillers in restorative resin-based materials. Dent Mater. 2019 Jan;35(1):3-14. https://doi.org/10.1016/i.dental.2018.08.288

10. Du M, Zheng Y. Zheng and Ying. Modification of silica nanoparticles and their application in UDMA dental polymeric composites. Polym Compos. 2007;28(2):10. https://doi.org/10.1002/pc.20377

11. Chiari MD, Rodrigues MC, Xavier TA, Souza EM, Arana-Chavez VE, Braga RR. Mechanical properties and ion release from bioactive restorative composites containing glass fillers and calcium phosphate nano-structured particles. Dent Mater. 2015 Jun;31(6):726-33 https://doi.org/10.1016/i.dental.2015.03.015

12. $\mathrm{Xu} \mathrm{HH}$ and Moreau JL. Dental glass-reinforced composite for caries inhibition: calcium phosphate ion release and mechanical properties. J Biomed Mater Res B Appl Biomater. 2010 Feb;92(2):332-40. https://doi.org/10.1002/jbm.b.31519.

13. Rodrigues MC, Xavier TA, Arana-Chavez VE, Braga RR. Polymer-based material containing calcium phosphate particles functionalized with a dimethacrylate monomer for use in restorative dentistry. J Biomater Appl. 2017 Jan;31(6):871-7. https://doi.org/10.1177/0885328216680116

14. O'Donnell JN, Schumacher GE, Antonucci JM, Skrtic D. Structure-composition-property relationships in polymeric amorphous calcium phosphate-based dental composites. Materials (Basel). 2009;2(4):1929-59. https://doi.org/10.3390/ma2041929

15. Labella R, Braden M, Deb S. Novel hydroxyapatite-based dental composites. Biomaterials. 1994 Dec;15(15):1197-200. https://doi.org/10.1016/0142-9612(94)90269-0

16. Antonucci JM, Liu DW, Skrtic D. Amorphous calcium phosphate based composites: effect of surfactants and poly(ethylene oxide) on filler and composite properties. J Dispers Sci Technol. 2007;28(5):819-24. https://doi.org/10.1080/01932690701346255

17. Rodrigues MC, Hewer TL, Brito GE, Arana-Chavez VE, Braga RR. Calcium phosphate nanoparticles functionalized with a dimethacrylate monomer. Mater Sci Eng C. 2014 Dec;45:122-6. https://doi.org/10.1016/i.msec.2014.08.066

18. Natale LC, Rodrigues MC, Alania Y, Chiari MD, Boaro LC, Cotrim M, et al. Mechanical characterization and ion release of bioactive dental composites containing calcium phosphate particles. J Mech Behav Biomed Mater. 2018 Aug;84(84):161-7. https://doi.org/10.1016/j.jmbbm.2018.05.022

19. Natale LC, Rodrigues MC, Alania Y, et al. Development of calcium phosphate/ethylene glycol dimethacrylate particles for dental applications. J Biomed Mater Res B Appl Biomater. 2018 Aug;2018: https://doi.org/10.1002/jbm.b.34164

20. Stansbury JW, Dickens SH. Determination of double bond conversion in dental resins by near infrared spectroscopy. Dent Mater. 2001 Jan;17(1):71-9. https://doi.org/10.1016/S0109-5641(00)00062-2

21. Chung SM, Yap AU, Koh WK, Tsai KT, Lim CT. Measurement of Poisson's ratio of dental composite restorative materials. Biomaterials. 2004 Jun;25(13):2455-60. https://doi.org/10.1016/j.biomaterials.2003.09.029

22. Scaramucci T, João-Souza SH, Lippert F, Eckert GJ, Aoki IV, Hara AT. Influence of toothbrushing on the antierosive effect of film-forming agents. Caries Res 2016 Mar;50:104-10. https://doi.org/10.1159/000443

23. Dorozhkin SV. Calcium orthophosphates in dentistry. J Mater Sci Mater Med. 2013 Jun;24(6):1335-63. https://doi.org/10.1007/s10856-013-4898-1 
Vilela MS, Bernal VL, Chagas LLC, VicchiFM, Aranha ACC, Arana-Chavez VE, et al.

24. Par M, Spanovic N, Tauböck TT, et al. Degree of conversion of experimental resin composites containing bioactive glass 45S5: the effect of post-cure heating. Sci Rep. 2019;9:17245. https://doi.org/10.1038/s41598-019-54035-y

25. Fu SY, Feng XQ, Lauke B, Mai YW. Effects of particle size, particle/matrix interface adhesion and particle loading on mechanical properties of particulate-polymer composites. Compos, Part B Eng. 2008;39(6):30. https://doi.org/10.1016/i.compositesb.2008.01.002

26. Yang SY, Piao YZ, Kim SM, Lee YK, Kim KN, Kim KM. Acid neutralizing, mechanical and physical properties of pit and fissure sealants containing melt-derived 45S5 bioactive glass. Dent Mater. 2013 Dec;29(12):1228-35. https://doi.org/10.1016/i.dental.2013.09.007

27. Braga RR, Yamamoto T, Tyler K, Boaro LC, Ferracane JL, Swain MV. A comparative study between crack analysis and a mechanical test for assessing the polymerization stress of restorative composites. Dent Mater. 2012 Jun;28(6):632-41. https://doi.org/10.1016/i.dental.2012.02.008

28. Hahnel S, Dowling AH, El-Safty S, Fleming GJ. The influence of monomeric resin and filler characteristics on the performance of experimental resin-based composites (RBCs) derived from a commercial formulation. Dent Mater. 2012 Apr;28(4):416-23. https://doi.org/10.1016/j.dental.2011.11.016

29. Salgado VE, Cavalcante LM, Moraes RR, Davis HB, Ferracane JL, Schneider LF. Degradation of optical and surface properties of resin-based composites with distinct nanoparticle sizes but equivalent surface area. J Dent. 2017 Apr;59(59):48-53. https://doi.org/10.1016/i.jdent.2017.02.008

30. Condon JR, Ferracane JL. In vitro wear of composite with varied cure, filler level, and filler treatment. J Dent Res. 1997 Jul;76(7):1405-11. https://doi.org/10.1177/00220345970760071101 